\title{
Evaluation of clinical significance of TP53, BCL-2, BAX and MEKI expression in 229 ovarian carcinomas treated with platinum-based regimen
}

\section{J Kupryjańczyk*,I,4, T Szymańska', R Mądry², A Timorek³, J Stelmachów ${ }^{3}$, G Karpińska ${ }^{4}$, A Rembiszewska',

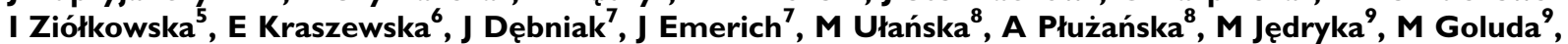

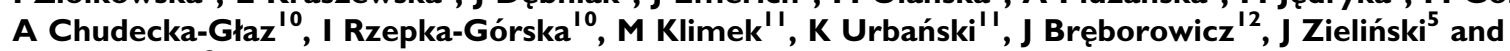 J Markowska ${ }^{2}$}

'Department of Molecular Pathology, Institute of Oncology, Roentgena 5, 02-78I Warsaw, Poland; ${ }^{2}$ Chair of Oncology, University of Medical Sciences, Poznań, Poland; ${ }^{3}$ Department of Obstetrics and Gynecology, Bródnowski Hospital and II-nd Faculty of Medicine, Medical University, Warsaw, Poland; ${ }^{4}$ Department of Pathology, Bródnowski Hospital and II-nd Faculty of Medicine, Medical University, Warsaw, Poland; ${ }^{5}$ Department of Gynecologic Oncology, Institute of Oncology, Roentgena 5, 02-78I Warsaw, Poland; ${ }^{6}$ Department of Biostatistics, Institute of Oncology, Roentgena 5, 02-78 1 Warsaw, Poland; ${ }^{7}$ II-nd Gynecological Department, Medical University, Gdańsk, Poland; ${ }^{8}$ Department of Chemotherapy, Medical University, Łodź, Poland; ${ }^{9}$ Il-nd Department of Gynecology, Medical Academy, Wrocław, Poland; ${ }^{10}$ Department of Gynecological Surgery and Oncology of Adults and Adolescent, Pomeranian Academy of Medicine, Szczecin, Poland; " Department of Gynecologic Oncology, Institute of Oncology, Kraków, Poland; ${ }^{12}$ Department of Pathology, University of Medical Sciences, Poznan', Poland

In cell line studies, BCL-2, BAX, as well as novel MEKI protein levels have strong influence on ovarian cancer response to cisplatinbased chemotherapy. However, such associations have not been demonstrated clinically. We evaluated prognostic/predictive significance of these proteins with regard to TP53 status. Immunohistochemical analysis was performed on 229 ovarian carcinomas FIGO stage IIB-IV treated with platinum-based chemotherapy; the results were analysed by the Cox and logistic regression models. Clinical parameters (residual tumour size, patient age, FIGO stage) were the only indicators of overall survival (OS) and the strongest predictors of complete remission (CR). On the other hand, BAX expression was the strongest $(P=0.005)$ or the only (in FIGO IIIC, $P=0.02)$ prognostic indicator of disease-free survival (DFS) in the TP53(+) group. TP53(+) and TP53(-) ovarian carcinomas differed in clinical and molecular prognostic and predictive factors. Another novel finding is that $\mathrm{CR}$ was negatively influenced by high BAX expression in all patients group $(P=0.047)$ and by BCL2 expression in the TP53 $(-)$ group $(P=0.05)$. High MEKI expression was associated with endometrioid and clear cell carcinomas $(P=0.049)$; its loss was found with advancing FIGO stage $(P=0.002)$. Our results suggest that binomial TP53 status divides ovarian carcinomas into two biologically distinct groups. BAX expression is an important factor of DFS in the TP53(+) group. BCL-2 and BAX, but not MEKI expressions have predictive value in ovarian cancer patients treated with platinum-based chemotherapy.

British Journal of Cancer (2003) 88, 848-854. doi: I0.I038/sj.bjc.6600789 www.bjcancer.com

(C) 2003 Cancer Research UK

Keywords: TP53; MEK; BCL-2; BAX; ovarian cancer

Cisplatin is the most commonly used chemotherapeutic compound in ovarian cancer patients and resistance to it is a major clinical problem in this condition (Christian and Trimble, 1994). Apoptosis is a predominant mechanism of tumour cell loss during chemotherapy, and its inefficiency may be an important cause of chemoresistance. Cisplatin induces apoptosis, which in a majority of ovarian carcinoma cell lines is TP53-dependent (Jones et al, 1998; Shimada et al, 2000). Impaired TP53 protein function, most frequently reflecting TP53 gene mutation contributes to resistance to cisplatin in ovarian carcinoma cell lines (Herod et al, 1996; Jones et al, 1998; Shimada et al, 2000), and the same could be expected clinically. Despite high frequency of TP53 gene mutations

*Correspondence: Dr J Kupryjańczyk; E-mail: jolantak@coi.waw.pl Revised 19 June 2002; accepted 19 November 2002 in ovarian carcinomas (Kupryjańczyk et al, 1993; 2000; Casey et al, 1996; DiCioccio et al, 1998; Wen et al, 1999), studies on TP53 status and tumour response to cisplatin-based chemotherapy have not so far given equivocal results (Righetti et al, 1996; de Feudis et al, 1997; Baekelandt et al, 1999; Eisenhauer et al, 1999; Fallows et al, 2001; Reles et al, 2001).

TP53 cooperates with apoptosis-regulating proteins in tumour response to cisplatin-based chemotherapy. $B C L-2$ expression (an apoptosis inhibitor) is downregulated, while $B A X$ expression (an apoptosis promoter) is upregulated by TP53 protein (Miyashita et al, 1994; Miyashita and Reed, 1995). It has also been shown that cisplatin-induced apoptosis is associated with wild-type TP53/BAX complex formation (Raffo et al, 2000). Cell line studies show that TP53-regulated protein levels may differ constitutionally and/or after cisplatin administration depending on the functional TP53 status (Herod et al, 1996; Jones et al, 1998). Thus, in multivariate 
analyses of prognostic and/or predictive factors, evaluating tumours together with functional and dysfunctional TP53 protein may possibly mask the biological significance of proteins regulated by or interacting with wild-type TP53 but not with mutant TP53.

Studies on ovarian carcinoma cell lines have revealed an association between high BCL-2 levels and resistance to cisplatin (Eliopoulos et al, 1995; Herod et al, 1996; Jones et al, 1998), however, contradictory results have been published, too (Beale et al, 2000); BAX expression either enhanced or did not influence ovarian carcinoma cell lines sensitivity to cisplatin (Jones et al, 1998; Beale et al, 2000). Despite these findings, significance of BCL-2 or BAX expression in ovarian cancer response to cisplatin-based chemotherapy has not been confirmed by clinical studies.

MEK is a relatively recently described apoptosis inhibitor. MEK (MEK1/MEK2 isoforms) is a MAP kinase kinase that plays a role in signal transduction from growth factors in a receptor tyrosine kinase - RAS - RAF-MEK-ERK cascade (Garrett and Workman, 1999). This cascade transmits both mitogen and antiapoptotic signals. It has been shown that MEK may stimulate antiapoptotic BCL-2, BCL-XL and MCL-1 proteins (Boucher et al, 2000), as well as inactivate proapoptotic protein BAD (Scheid and Duronio, 1998). Cell line studies on the role of MEK kinase in tumour response to cisplatin-based chemotherapy are controversial: in some studies MEK1 inhibited (Hong et al, 1999), in others activated TP53-dependent apoptosis after cisplatin administration; in the latter case the apoptosis was completely blocked by MEK1 inhibitors (Ryan et al, 2000; Wang et al, 2000).

Analyses of TP53 and/or apoptosis proteins in large groups of ovarian carcinomas are rare (Hartmann et al, 1994; Eltabbakh et al, 1997; Marx et al, 1997; Baekelandt et al, 1999, 2000; Ferrandina et al, 1999). To our knowledge, MEK1 expression and its clinical significance have not been evaluated yet in ovarian carcinomas. In this study, we present an analysis of the clinical significance of TP53 accumulation and expression of proteins interacting with TP53 in tumour response to cisplatin, that is BCL-2, BAX and MEK1. We also present an alternative approach to the analysis of prognostic and predictive factors in ovarian carcinomas by eliminating variability of the TP53 status.

\section{MATERIALS AND METHODS}

\section{Patients and tumours}

The study was performed on archival ovarian carcinomas from 229 patients treated in eight gynaecologic oncology centres in Poland. The material was carefully selected out of 548 cases submitted to meet the following criteria: no chemotherapy before staging laparotomy, adequate staging procedure, FIGO stage IIB to IV, standard CP (cisplatin-cyclophosphamide or carboplatin-cyclophosphamide) or CAP chemotherapy (CP with addition of doxorubicin), and tumour tissue from the first laparotomy available. Medical records were critically reviewed by at least two clinicians. Patients ranged in age 24-77 years (median 53.2). Tumours were staged according to the criteria of the International Federation of Gynaecologists and Obstetricians (Creasman, 1989) (Table 1). All tumours were uniformly reviewed histopathologically, classified according to the criteria of the World Health Organization (Russell, 1994) and graded in a four-grade scale according to the criteria given by (Barber et al, 1975) (Table 1).

Follow-up time was stated on the basis of patient's date of death or the last information present in medical records. Follow-up time ranged 1.44-146.7 months (median 24.7) and 168 patients have died $(73 \%)$. Follow-up time for the group of still alive patients ranged 7-146.7 months (median 41). Patients outcome is shown in Table 1.
Table I Tumour characteristics in the TP53-negative and TP53-positive group

\begin{tabular}{|c|c|c|c|}
\hline & $\begin{array}{c}\text { TP53(-) } \\
N=94\end{array}$ & $\begin{array}{c}\text { TP53(+) } \\
N=135\end{array}$ & $P$-value \\
\hline \multicolumn{4}{|l|}{ Age } \\
\hline $\begin{array}{l}\text { Range } \\
\text { mean (s.d.) }\end{array}$ & $\begin{array}{c}24-76 \\
52.4(11.1)\end{array}$ & $\begin{array}{r}25-77 \\
53.7(9.9)\end{array}$ & 0.57 \\
\hline \multicolumn{4}{|l|}{ FIGO stage } \\
\hline$\| B$ & $4(4 \%)$ & $6(4 \%)$ & \\
\hline$\| C$ & $2(2 \%)$ & $5(4 \%)$ & \\
\hline$\| \mathrm{A}$ & $4(4 \%)$ & $4(3 \%)$ & 0.8 \\
\hline$\| I B$ & $19(20 \%)$ & $26(19 \%)$ & \\
\hline$\| I C$ & $51(54 \%)$ & $78(58 \%)$ & \\
\hline IV & $14(15 \%)$ & $16(12 \%)$ & \\
\hline \multicolumn{4}{|l|}{ Residual tumour } \\
\hline $0-2 \mathrm{~cm}$ & 44 (47\%) & 65 (48\%) & 0.92 \\
\hline$>2 \mathrm{~cm}$ & $50(53 \%)$ & $70(52 \%)$ & \\
\hline \multicolumn{4}{|l|}{ Histological type } \\
\hline Serous & $63(67 \%)$ & $114(84 \%)$ & \\
\hline Endometrioid & $9(10 \%)$ & $5(4 \%)$ & 0.001 \\
\hline Clear cell & $12(13 \%)$ & & \\
\hline Undifferentiated & $5(5 \%)$ & $8(7 \%)$ & \\
\hline Other & $5(5 \%)$ & $7(5 \%)$ & \\
\hline \multicolumn{4}{|l|}{ Histological grade } \\
\hline G2 & $19(20 \%)$ & || (8\%) & \\
\hline G3 & $55(59 \%)$ & 87 (64\%) & 0.032 \\
\hline G4 & $20(21 \%)$ & $37(27 \%)$ & \\
\hline \multicolumn{4}{|l|}{ Chemotherapy } \\
\hline $\mathrm{CP}$ & $70(75 \%)$ & $95(70 \%)$ & \\
\hline CAP & $24(25 \%)$ & $40(30 \%)$ & \\
\hline \multicolumn{4}{|l|}{ Response to chemotherapy } \\
\hline Complete remission & $46(49 \%)$ & $74(55 \%)$ & \\
\hline Partial remission & $11(12 \%)$ & $24(18 \%)$ & \\
\hline No change & $4(4 \%)$ & $4(3 \%)$ & \\
\hline Progression & $33(35 \%)$ & $33(24 \%)$ & \\
\hline Platinum resistant & $53(56 \%)$ & 77 (57\%) & \\
\hline Platinum sensitive & $41(44 \%)$ & $58(43 \%)$ & \\
\hline $\begin{array}{l}\text { Recurrence rate in } \\
\text { a CR group }\end{array}$ & $34 / 46(74 \%)$ & $58 / 74(78 \%)$ & \\
\hline \multicolumn{4}{|l|}{ Outcome } \\
\hline NED & $12(13 \%)$ & $23(17 \%)$ & \\
\hline AWD & $9(10 \%)$ & $17(13 \%)$ & \\
\hline DOD & $70(75 \%)$ & 94 (70\%) & \\
\hline $\mathrm{DOC}$ & $3(3 \%)$ & I (I\%) & \\
\hline
\end{tabular}

$\overline{\mathrm{CP}=\text { cyclophosphamide and cisplatin, } \mathrm{CAP}=\mathrm{CP} \text { plus doxorubicin, } \mathrm{CR}=\text { complete }}$ remission, $N E D=$ no evidence of disease, $A W D=$ alive with disease, $D O D=$ died of disease, $\mathrm{DOC}=$ died of other causes, ${ }^{2} \chi^{2}$ test.

\section{Evaluation of clinical response to chemotherapy}

Response to chemotherapy was evaluated retrospectively according to the World Health Organization response evaluation criteria (Miller et al, 1981). The evaluation was based on data from medical records describing patient's clinical condition and CA125 levels in 3-4 week intervals. Complete remission (CR) was defined as disappearance of all clinical and biochemical symptoms of ovarian cancer evaluated after completion of first-line chemotherapy and confirmed at 4 weeks. Within the $\mathrm{CR}$ group we have defined a platinumsensitive (PS) group (disease-free survival (DFS) longer than 6 months, 99 patients). The other tumours (partial remission - PR, 
progression - P, no change - NC), as well as the CR group with DFS shorter than 6 months were described as resistant to cisplatin (Christian and Trimble, 1994) (Table 1).

\section{Immunohistochemical analysis}

All immunohistochemical stainings were performed on paraffinembedded material after heat-induced epitope retrieval (HIER). Owing to the multicenter origin of paraffin blocks, all tumours were checked as to the immunoreactivity by staining for vimentin. Intratumoural inflammatory infiltrate stained for BCL-2 and BAX was a control for tissue immunoreactivity, too. We used PAb1801 monoclonal antibody ( $1: 500$, Sigma-Genosys, Cambridge, UK) for TP53 protein, anti-MEK1 (clone $\mathrm{H}-8$ ) and anti-BAX (clone B-9) monoclonal antibodies (both $1: 80$, Santa Cruz Biotechnology Inc, Santa Cruz, USA), anti-BCL-2 monoclonal antibody ( $1: 80$, clone 124, Dako, Glostrup, Denmark) and antivimentin monoclonal antibody (1:50, clone V9, Immunotech, Marseille, France). Deparaffinised sections were boiled in a citrate buffer $(\mathrm{pH} 6.0)$ at $700 \mathrm{~W}$ in a microwave: $2 \times 5 \mathrm{~min}$ for TP53 and vimentin, $3 \times 5 \mathrm{~min}$ for BCL-2 and $6 \times 5 \mathrm{~min}$ for BAX; for MEK1 detection, the sections were boiled in the same buffer for $30 \mathrm{~s}$ at $120^{\circ} \mathrm{C}$ and $15 \mathrm{psi}$ in an autoclave. Nonspecific tissue and endogenous peroxidase reactivity were blocked with $10 \% \mathrm{BSA}$ and $3 \% \mathrm{H}_{2} \mathrm{O}_{2}$, respectively. Tissue sections were incubated with primary antibodies for $1 \mathrm{~h}$ at room temperature (antivimentin, anti-BCL-2 and anti-TP53) or overnight at $4^{\circ} \mathrm{C}$ (the other). Biotinylated goat anti-mouse $\operatorname{IgG}(1: 1500$, cat. no. 816), peroxidase-conjugated streptavidin $(1: 500$, cat. no. 309) (both from Immunotech, Marseille, France) and DAB were used as a detection system. Ovarian carcinomas with and without TP53 gene mutation were controls for TP53. Intratumoural lymphocytes and plasma cells, as well as a tonsil tissue were controls for BCL-2 and/or BAX. Normal salpingeal mucosa from three cases studied served as a positive control for MEK1; antiWAF1 monoclonal antibody from the same company as antiMEK1, detecting a nuclear antigen served as an isotype-matched antibody for anti-MEK1. Normal mouse IgG of the same subclasses and concentrations as the primary antibodies served as negative controls, too.

Semiquantitative evaluation of immunohistochemical stainings was performed independently by two pathologists (JK, TSZ). TP53 protein accumulation was described as present (more than $10 \%$ of positive cells) or absent. BAX and MEK1 expressions were described as: (1) negative, trace or weak (further called low), (2) moderate and (3) strong (both further called high). BCL-2 expression was described as: (1) negative or focal, and (2) positive.

\section{Statistical analysis}

Probability of survival and DFS were estimated using the KaplanMeier method (Kaplan and Meier, 1958). Overall and DFS time analyses were performed with multivariate Cox's proportional hazards models (Cox, 1972); tumour response to chemotherapy (probability of CR, probability of PS response) was evaluated with the multivariate logistic regression model. Important factors were selected using backward selection technique, where factors not significant at 0.1 were drawn one by one out of the model. The analysis was performed in all ovarian carcinomas, and separately in the TP53(-) and TP53(+) subgroups. To eliminate an influence of stage parameter, we evaluated separately FIGO IIIC group, too.

Associations between protein expressions and histological type, grade, FIGO stage and residual tumour size were studied by $\chi^{2}$ test (Mehta and Patel, 1983). All tests were two-sided and the level of significance was set at $5 \%$. All calculations were done using the STATA 6.0 program.

\section{RESULTS}

\section{TP53, BCL-2, BAX and MEK1 associations}

TP53 protein accumulation was observed in malignant cells only, while the other proteins, that is BCL-2, BAX and MEK1 were expressed by normal cells or tissues, as well. In particular, MEK1 protein was expressed by mucosa of the uterine tube and inconstantly by fibroblasts and mesothelium. BCL-2 showed heterogeneous, cytoplasmic staining; BAX and MEK1 showed cytoplasmic rather homogeneous staining.

TP53 protein nuclear accumulation was present in $135(59 \%)$ tumours. BCL-2 was negative in majority of cases $(N=156 ; 68 \%)$; it was positive in 73 cases (32\%). BAX expression was low in 85 $(37 \%)$ cases; it was moderate in $57(25 \%)$ and strong in $87(38 \%)$ cases. MEK1 expression was low in 52 tumours (23\%); it was moderate in $98(43 \%)$ and strong in $79(34 \%)$ tumours (Figure 1). BCL-2, BAX and MEK1 protein expressions were not associated with each other, neither with TP53 protein accumulation.

Associations of protein expressions with histological tumour types are shown in Table 2. Poor tumour differentiation/ undifferentiation was associated with TP53 protein accumulation $(P=0.032)$ and high BAX positivity $(P=0.018)$. BCL-2 and MEK1 expressions did not correlate with tumour grade.

Loss of intensity of MEK1 expression was apparent concomitantly with advancing FIGO stage (100\% high positivity for IIB and IIC, $91 \%$ for IIIA and IIIB, $70 \%$ for IIIC and IV) $(P=0.002)$. Other protein expressions did not correlate with FIGO stage.

\section{Overall survival analysis}

Overall survival was associated with clinical parameters and not with any protein expression studied. Overall survival in the whole group was influenced by patient age, FIGO stage and residual

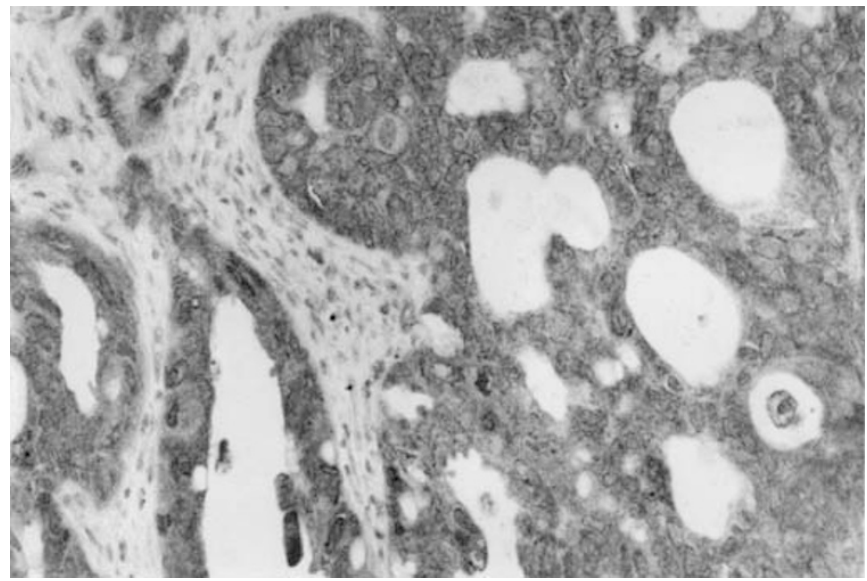

Figure I Strong cytoplasmic MEKI expression in an endometrioid carcinoma of the ovary (haematoxylin counterstain, $\times 250$ ).

Table 2 Associations of protein expressions with histological tumour types

\begin{tabular}{lcccc}
\hline & $\begin{array}{c}\text { Serous } \\
\text { (\%) }\end{array}$ & $\begin{array}{c}\text { Undifferentiated } \\
\text { and other (\%) }\end{array}$ & $\begin{array}{c}\text { Endometrioid } \\
\text { and clear cell (\%) }\end{array}$ & P-value \\
\hline TP53 positive & 66 & 61 & 30 & 0.001 \\
BCL-2 positive & 27 & 28 & 62 & 0.003 \\
$\begin{array}{l}\text { BAX highly } \\
\text { positive }\end{array}$ & 59 & 85 & 65 & 0.043 \\
$\begin{array}{c}\text { MEKI highly } \\
\text { positive }\end{array}$ & 75 & 77 & 96 & 0.049 \\
\hline
\end{tabular}


Table 3 Overall survival (risk of death) in the whole group of ovarian carcinomas, and in the TP53(+) and TP53(-) group (Cox's proportional hazards model)

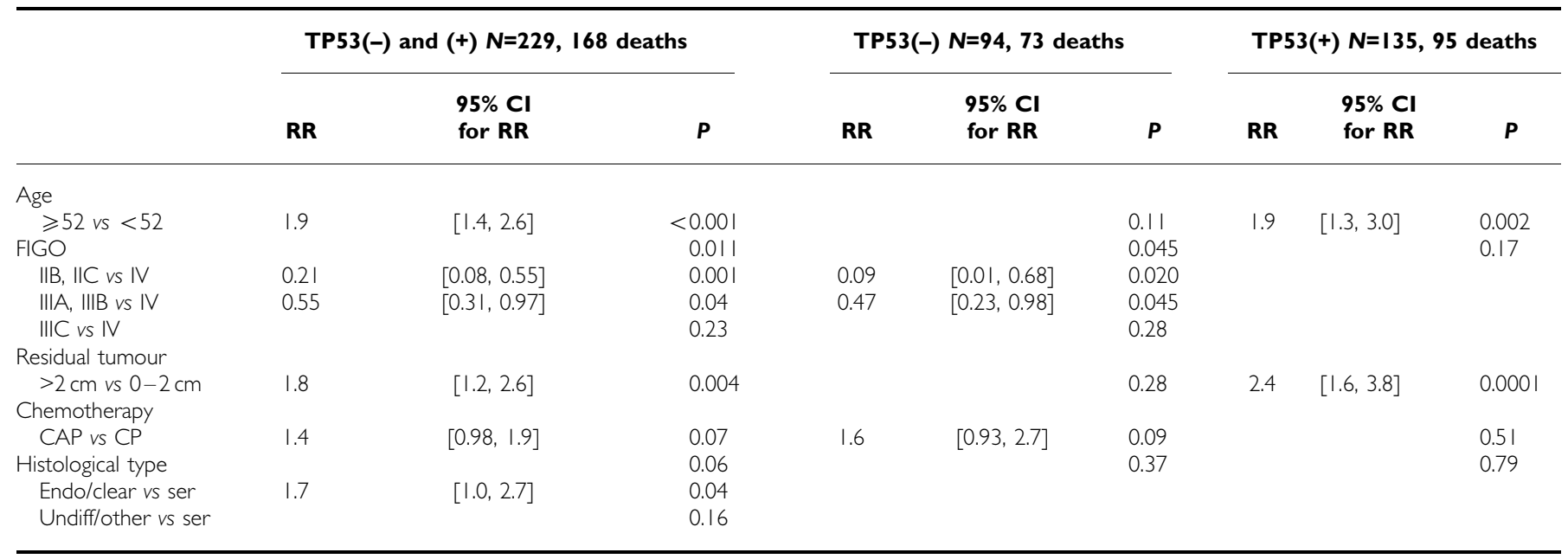

Endo/clear=endometrioid or clear cell; ser=serous; undiff/other=undifferentiated or other types.

Table 4 Overall survival (risk of death) in FIGO IIIC ovarian carcinomas, and in the group IIIC divided according to TP53 status (Cox's proportional hazards model)

\begin{tabular}{|c|c|c|c|c|c|c|c|c|c|}
\hline & \multicolumn{3}{|c|}{ TP53(-) and $(+) N=|29,10|$ deaths } & \multicolumn{3}{|c|}{ TP53(-) $N=5 I, 4 \mid$ deaths } & \multicolumn{3}{|c|}{ TP53(+) N=78, 60 deaths } \\
\hline & $\mathbf{R R}$ & $\begin{array}{l}95 \% \mathrm{Cl} \\
\text { for } \mathrm{RR}\end{array}$ & $P$ & $\mathbf{R R}$ & $\begin{array}{l}95 \% \mathrm{Cl} \\
\text { for RR }\end{array}$ & $P$ & $\mathbf{R R}$ & $\begin{array}{l}95 \% \mathrm{Cl} \\
\text { for RR }\end{array}$ & $P$ \\
\hline \multicolumn{10}{|l|}{ Age } \\
\hline $\begin{array}{l}\geqslant 52 \text { vs }<52 \\
\text { Chemotherapy }\end{array}$ & 3.1 & {$[2.0,4.7]$} & $<0.001$ & 3.1 & {$[1.6,5.9]$} & $<0.001$ & 2.9 & {$[1.7,5.0]$} & $<0.001$ \\
\hline
\end{tabular}

Table 5 Probability of CR in the whole group of ovarian carcinomas, and in the TP53(+) and TP53(-) group (logistic regression model)

\begin{tabular}{|c|c|c|c|c|c|c|c|c|c|}
\hline & \multicolumn{3}{|c|}{ TP53(-) and (+) N=229, I $20 \mathrm{CR}$} & \multicolumn{3}{|c|}{ TP53(-) N=94, $46 \mathrm{CR}$} & \multicolumn{3}{|c|}{ TP53(+) $N=135,74 \mathrm{CR}$} \\
\hline & OR & $\begin{array}{l}95 \% \mathrm{Cl} \\
\text { for OR }\end{array}$ & $\mathbf{P}$ & OR & $\begin{array}{l}95 \% \mathrm{Cl} \\
\text { for OR }\end{array}$ & $\mathbf{P}$ & OR & $\begin{array}{l}95 \% \mathrm{Cl} \\
\text { for OR }\end{array}$ & $P$ \\
\hline \multicolumn{10}{|l|}{ Age } \\
\hline $\begin{array}{r}\geqslant 52 \text { vs }<52 \\
\text { Residual tumour }\end{array}$ & 0.49 & {$[0.27,0.89]$} & 0.019 & 0.36 & {$[0.14,0.88]$} & 0.026 & & & 0.28 \\
\hline$\underset{B A X}{>2 \mathrm{~cm} \text { vs } 0-2 \mathrm{~cm}}$ & 0.16 & {$[0.08,0.33]$} & $<0.001$ & 0.27 & {$[0.11,0.68]$} & 0.005 & 0.10 & {$[0.04,0.22]$} & $<0.001$ \\
\hline $\begin{array}{l}\text { High (+) vs low }(+) \\
\text { BCL-2 }\end{array}$ & 0.53 & {$[0.29,0.99]$} & 0.047 & & & 0.52 & & & 0.13 \\
\hline$(+)$ vs $(-)$ & & & 0.14 & 0.4 & {$[0.16,1.01]$} & 0.05 & & & 0.99 \\
\hline
\end{tabular}

tumour (RT) size (Table 3). In addition, risk of death was higher in cases with endometrioid and clear cell-type carcinoma of the ovary when compared with the serous ones.

Overall survival analysis in the TP53(+) and TP53(-) subgroups revealed two prognostically different classes of ovarian carcinomas (Table 3; only variables showing associations in at least one analysis are shown in the tables). Overall survival was negatively associated with higher patient age and larger RT in the TP53(+) group, but not in the TP53(-) group. FIGO stage influenced OS in the TP53(-) group, but not in the TP53(+) group.

Chemotherapy with the addition of doxorubicin compared with $\mathrm{CP}$ regimen showed a tendency to increased risk of death in all patients group $(P=0.07)$ (Table 3$)$. It turned out in further analysis that FIGO stage IIIC TP53(-) group showed higher probability of death when treated with CAP chemotherapy (Table 4). The only factor that consequently influenced OS in the FIGO IIIC group was patient age (Table 4).

\section{Complete remission and platinum sensitivity}

Complete remission (CR) was achieved in 120 patients (52\%), while PS response (CR with DFS longer than 6 months) was achieved in 99 of 229 patients (43\%). Clinical parameters were the strongest predictors of CR (Table 5) and the only predictors of PS 
response. Nevertheless, CR was associated with the apoptosis proteins, too.

Complete remission status was associated with small RT size in all three groups analysed (Table 5). It was also associated with lower patient age in the whole group and in the TP53(-) group. Complete remission status was associated with low BAX staining in the whole group, and with negative BCL-2 staining in the TP53(-) group. The only factor that influenced probability of $\mathrm{CR}$ in the TP53(+) group was RT size (Table 3).

Platinum sensitivity showed associations with small RT at the same $P$ level as CR; PS was also associated with FIGO stage IIB or IIC in the whole group $(P=0.02)$ and in the TP53(+) group $(P=0.05)$, as well as with patient age in the whole group only $(P=0.017)$. Low BAX expression showed a tendency to increase probability of PS in the TP53(-) group, but it was at the border of significance $(P=0.07)$. Other factors did not influence response to chemotherapy.

\section{Disease-free survival analysis}

In the whole group of patients with $\mathrm{CR}(N=120,92$ with recurrences), DFS was influenced by FIGO stage only $(P=0.0005)$.

In the TP53(+) group (74 with $\mathrm{CR}, 58$ with recurrences) $\mathrm{BAX}$ expression was the strongest or the only (in FIGO IIIC, $P=0.02$ ) prognostic indicator of DFS. In this group, DFS was longer with lower FIGO stage $(P=0.01)$ and with high BAX expression $(P=0.005, \mathrm{RR}=0.45,95 \% \mathrm{CI}$ for RR: $[0.25,0.78])$. This tendency has been confirmed in the TP53(+) FIGO IIIC group (39 with CR, 32 with recurrences), that is after elimination of clinical stage parameter: strong (not generally high) BAX expression had positive influence on DFS $(P=0.02, \mathrm{RR}=0.39,95 \% \mathrm{CI}$ for $\mathrm{RR}$ : $[0.17,0.88])$. Strong BAX expression in the TP53(+) group was the only parameter that influenced DFS in FIGO IIIC group.

In the TP53(-) group (46 with CR, 34 with recurrences) DFS was longer with lower residual tumour, at the border of significance $(P=0.06)$. The other factors included into the analysis did not influence DFS time.

\section{DISCUSSION}

In cell line studies, BCL-2, BAX, as well as novel MEK1 protein levels have strong influence on ovarian cancer response to cisplatin-based chemotherapy. With a single exception related to BCL-2 expression (Mano et al, 1999), such associations have not been demonstrated clinically. To our knowledge, this is the first evidence of influence of BAX and BCL-2 expression on CR in ovarian cancer patients, confirmed by multivariate analysis. BAX expression, in contrast to its apoptosis promoter function and similarly to BCL-2 expression had negative impact on CR. Similar discrepancy between biological function of apoptosis proteins and their clinical significance has been previously observed by Marx et al (1997) who found a bad prognostic significance of BAX expression, and a good one of BCL-2 expression.

In the current study, negative impact of BCL-2 expression on CR was demonstrated in the TP53-negative carcinomas only, confirming our hypothesis that TP53-positive and TP53-negative ovarian carcinomas differ in clinical significance of apoptosis proteins interacting with TP53 in tumour response to cisplatinbased chemotherapy. In subgroups related to the TP53 status, BCL-2 and BAX demonstrated an influence on CR or DFS, which was not seen in all tumours. Among other studies evaluating predictive significance of BCL-2 (Herod et al, 1996; Mano et al, 1999; Schuyer et al, 2001), including two published by Baekelandt et al $(1999,2000)$ on a comparable number of ovarian carcinomas, only Mano et al (1999) noticed higher frequency of CR in patients with BCL-2 negative tumours.
In regard to BAX expression, a few studies have addressed the issue of its clinical significance in advanced stage ovarian carcinomas; however, associations with CR or DFS have not been observed (Marx et al, 1997; Baekelandt et al, 2000; Sengupta et al, 2000; Schuyer et al, 2001). Recently, Schuyer et al (2001) found an association of BAX expression with progression-free survival.

Interestingly, TP53-positive and TP53-negative carcinomas demonstrated striking differences not only in relation to immunohistochemical markers, but also to clinical parameters. After division of ovarian carcinomas into TP53-negative and TP53positive, prognostic significance of patient age, FIGO stage, residual tumour size and histological tumour type either disappeared or became weaker or stronger, depending on the group. As a factor of OS, FIGO stage appeared to be an alternative to patient age. This has been supported by the analysis of FIGO IIIC group only, in which patient age was a constant prognostic factor irrespective of TP53 status. Apparently, the differing results for the TP53-negative and TP53-positive carcinomas were not influenced by differences in clinicopathological characteristics, since both groups were very similar. Nevertheless, the tendencies revealed by subgroup analysis should be confirmed on larger population.

Despite the novel findings related to TP53 and apoptosis proteins, clinical parameters were the only factors of OS, the strongest predictors of $\mathrm{CR}$ and the only predictors of platinum sensitivity. In particular, residual tumour size was a constant and important parameter influencing CR. The strong impact of clinical parameters on clinical end points in our analysis is in agreement with other studies (Makar et al, 1995; Partridge et al, 1996; Eisenhauer et al, 1999). Usually, immunohistochemical markers present lower associations with clinical end points than clinical parameters (Diebold et al, 1996; Herod et al, 1996; Baekelandt et al, 1999, 2000; Mano et al, 1999; Geisler et al, 2000; Reles et al, 2001; Schuyer et al, 2001). In our analysis, the only exception was the positive influence of high BAX expression on DFS in patients with TP53-positive ovarian carcinomas - it was stronger than that of the FIGO stage. After elimination of stage factor (TP53-positive FIGO IIIC group only) BAX expression was the only parameter that influenced DFS.

Evaluation of clinical significance of MEK1 and TP53 expression has generally brought negative results, confirming that observations from cell line studies cannot be directly referred to clinical situations. As far as TP53 is concerned, in the literature there are few studies on clinical significance of TP53 protein accumulation in large groups of advanced stage ovarian carcinomas (Hartmann et al, 1994; Eltabbakh et al, 1997; Baekelandt et al, 1999; Ferrandina et al, 1999; Shahin et al, 2000; Reles et al, 2001). Two of three of those research groups who related TP53 protein accumulation to tumour response to platinum-based chemotherapy have found better response in TP53-negative tumours (Ferrandina et al, 1999; Reles et al, 2001). Baeklandt et al (1999) have shown a prognostic but not predictive significance of TP53 protein accumulation, while other authors did not find any clinical significance of the TP53 protein (Hartmann et al, 1994; Eltabbakh et al, 1997; Shahin et al, 2000). Similarly, in our study TP53 expression by itself did not show any clinical significance. Interestingly though, our results suggest that impaired TP53 protein function may level or enhance prognostic or predictive significance of other factors. Platinum compounds and taxanes that are currently applied as a standard treatment in ovarian cancer patients have different molecular targets. There is a pilot study showing that tumours with TP53 gene mutations show better response to paclitaxel than tumours with wt TP53 (Lavarino et al, 2000); the reverse is observed by some authors in relation to cisplatin (as above). It seems that separate evaluation of TP53-positive and TP53-negative subgroups may help to identify molecular profiles of tumours, which will show differential response to different chemotherapeutic regimens. 


\section{ACKNOWLEDGEMENTS}

This study was supported by Grants no. 4P05C 02814 and 6 P05E 11921 from the Polish Committee for Scientific Research. The authors express their gratitude to pathologists who provided paraffin tissue blocks for this study, Professor Professor M Chrabowska, J Rabczyński, A Niezabitowski, J Lubiński, A Kulig, W Olszewski, Dr Dr M Cikowska-Woźniak, L Giernat.

\section{REFERENCES}

Baekelandt M, Holm R, Nesland JM, Trope CG, Kristensen GB (2000) Expression of apoptosis - related proteins is an independent determinant of patient prognosis in advanced ovarian cancer. J Clin Oncol 18: $3775-3781$

Baekelandt M, Kristensen GB, Nesland JM, Trope CG, Holm R (1999) Clinical significance of apoptosis - related factors p53, Mdm2, and bcl-2 in advanced ovarian cancer. J Clin Oncol 17: 2061-2068

Barber HR, Sommers SC, Snyder R, Kwon TH (1975) Histologic and nuclear grading and stromal reactions as indices for prognosis in ovarian cancer. Am J Obstet Gynecol 121: 795-807

Beale PJ, Rogers P, Boxall F, Sharp SY, Kelland LR (2000) Bcl-2 family protein expression and platinum drug resistance in ovarian carcinoma. Br J Cancer 82: 436 - 440

Boucher MJ, Morisset J, Vachon PH, Reed JC, Laine J, Rivard N (2000) MEK/ERK signaling pathway regulates the expression of bcl-2, bcl-X(L), and Mcl-1 and promotes survival of human pancreatic cancer cells. J Cell Biochem 79: $355-369$

Casey G, Lopez ME, Ramos JC, Plummer SJ, Arboleda MJ, Shaughnessy M, Karlan B, Slamon DJ (1996) DNA sequence analysis of exons 2 through 11 and immunohistochemical staining are required to detect all known p53 alterations in human malignancies. Oncogene 13: 1971-1981

Christian MC, Trimble EL (1994) Salvage chemotherapy for epithelial ovarian carcinoma. Gynecol Oncol 55(Suppl): S143-S150

Cox DR (1972) Regression models and life tables (with discussion). J R Stat Soc 34: $187-220$

Creasman WJ (1989) Announcement, FIGO stages 1988, Revisions. Gynecol Oncol 35: $125-127$

de Feudis P, Debernardis D, Beccaglia P, Valenti M, Graniela Sire E, Arzani D, Stanzione S, Parodi S, D'incalci M, Russo P, Broggini M (1997) DDPinduced cytotoxicity is not influenced by $\mathrm{p} 53$ in nine human ovarian cancer cell lines with different p53 status. Br J Cancer 76: 474-479

DiCioccio RA, Werness BA, Peng R, Allen HJ, Piver MS (1998) Correlation of TP53 mutations and p53 expression in ovarian tumours. Cancer Genet Cytogenet 105: $93-102$

Diebold J, Baretton G, Felchner M, Meier W, Dopfer K, Schmidt M, Lohrs U (1996) Bcl-2 expression, p53 accumulation, and apoptosis in ovarian carcinomas. Am J Clin Pathol 105: 341 - 349

Eisenhauer EA, Gore M, Neijt JP (1999) Ovarian cancer: should we be managing patients with good and bad prognostic factors in the same manner? Ann Oncol 10 (Suppl): S9-S15

Eliopoulos AG, Kerr DJ, Herod J, Hodgkins L, Krajewski S, Reed JC, Young LS (1995) The control of apoptosis and drug resistance in ovarian cancer: influence of p53 and bcl-2. Oncogene 11: 1217-1228

Eltabbakh GH, Belinson JL, Kennedy AW, Biscotti CV, Casey G, Tubbs RR, Blumenson LE (1997) p53 overexpression is not an independent prognostic factor for patients with primary ovarian epithelial cancer. Cancer 80: $892-898$

Fallows S, Price J, Atkinson RJ, Johnston PG, Hickey I, Russel SE (2001) p53 Mutation does not affect prognosis in ovarian epithelial malignancies. J Pathol 194: 68 -75

Ferrandina G, Fagotti A, Salerno MG, Natali PG, Mottolese M, Maneschi F, De Pasqua A, Benedetti-Panici P, Mancuso S, Scambia G (1999) p53 Overexpression is associated with cytoreduction and response to chemotherapy in ovarian cancer. Br J Cancer 81: 733-740

Garrett MD, Workman P (1999) Discovering novel chemotherapeutic drugs for the third millennium. Eur J Cancer 35: 2010-2030

Geisler JP, Geisler HE, Miller GA, Wiemann MC, Zhou Z, Crabtree W (2000) p53 and bcl-2 in epithelial ovarian carcinoma: their value as prognostic indicators at a median follow-up of 60 months. Gynecol Oncol 77: $278-282$

Hartmann LC, Podratz KC, Keeney GL, Kamel NA, Edmonson JH, Grill JP, Su JQ, Katzmann JA, Roche PC (1994) Prognostic significance of p53 immunostaining in epithelial ovarian cancer. J Clin Oncol 12: $64-69$
Herod JJO, Eliopoulos AG, Warwick J, Niedobitek G, Young LS, Kerr DJ (1996) The prognostic significance of bcl-2 and p53 expression in ovarian carcinoma. Cancer Res 56: 2178-2184

Hong M, Lai MD, Lin YS, Lai MZ (1999) Antagonism of p53-dependent apoptosis by mitogen signals. Cancer Res 59: 2847-2852

Jones NA, Turner J, McIlwrath AJ, Brown R, Dive C (1998) Cisplatin- and paclitaxel-induced apoptosis of ovarian carcinoma cells and the relationship between bax and bak up-regulation and the functional status of p53. Mol Pharmacol 53: 819-826

Kaplan EL, Meier P (1958) Non-parametric estimation from incomplete observations. J Am Stat Assoc 53: 457-481

Kupryjańczyk J, Thor AD, Beauchamp R, Merritt V, Edgerton SM, Bell DA, Yandell DW (1993) p53 Gene mutations and protein accumulation in human ovarian cancer. Proc Natl Acad Sci USA 90: 4961-4965

Kupryjańczyk J, Dansonka-Mieszkowska A, Szymańska T, Karpińska G, Rembiszewska A, Rusin M, Konopiński R, Kraszewska E, Timorek A, Yandell DW, Stelmachów J (2000) Spontaneous apoptosis in ovarian carcinomas: a positive association with $p 53$ gene mutation is dependent on growth fraction. Br J Cancer 82: 579-583

Lavarino C, Pilotti S, Oggionni M, Gatti L, Perego P, Bresciani G, Pierotti MA, Scambia G, Ferrandina G, Fagotti A, Mangioni C, Lucchini V, Vecchione F, Bolis G, Scarfone G, Zunino F (2000) p53 Gene status and response to platinum/paclitaxel-based chemotherapy in advanced ovarian carcinoma. J Clin Oncol 18: 3936-3945

Makar A, Baekelandt M, Trope CG, Kristensen GB (1995) The prognostic significance of residual disease, figo substage, tumor histology, and grade in patients with figo stage III ovarian cancer. Gynecol Oncol 56: 175-180

Mano Y, Kikuchi Y, Yamamoto K, Kita T, Hirata J, Tode T, Ishii K, Nagata I (1999) Bcl-2 as a predictor of chemosensitivity and prognosis in primary epithelial ovarian cancer. Eur J Cancer 35: 1214-1219

Marx D, Binder C, Meden H, Lenthe T, Ziemek T, Hiddemann T, Kuhn W, Schauer A (1997) Differential expression of apoptosis associated genes bax and bcl-2 in ovarian cancer. Anticancer Res 17: 2233-2240

Mehta CR, Patel NR (1983) A network algorithm for the exact treatment of Fisher's exact test in RxC contingency tables. J Am Stat Assn 78: 427-434

Miller AB, Hogestraeten B, Staquet M, Winkler A (1981) Reporting results of cancer treatment. Cancer 47: 207-214

Miyashita T, Krajewski S, Krajewska M, Wang HG, Lin HK, Liebermann DA, Hoffman B, Reed JC (1994) Tumour suppressor p53 is a regulator of bcl-2 and bax gene expression in vitro and in vivo. Oncogene 9: $1799-1805$

Miyashita T, Reed JC (1995) Tumour suppressor p53 is a direct transcriptional activator of the human bax gene. Cell 80: 293-299

Partridge EE, Phillips JL, Menck HR (1996) The national cancer data base report on ovarian cancer treatment in United States Hospitals. Cancer 78: $2236-2246$

Raffo AJ, Kim AL, Fine RL (2000) Formation of nuclear bax/p53 complexes is associated with chemotherapy induced apoptosis. Oncogene 19: 62166228

Reles A, Wen WH, Schmider A, Gee C, Runnebaum IB, Kilian U, Jones LA, El-Naggar A, Minguillon C, Schönborn I, Reich O, Kreienberg R, Lichtenegger W, Press MF (2001) Correlation of p53 mutations with resistance to platinum-based chemotherapy and shortened survival in ovarian cancer. Clin Cancer Res 7: 2984-2997

Righetti SC, Della Torre G, Pilotti S, Menard S, Ottone F, Colnaghi MI, Pierotti MA, Lavarino C, Cornarotti M, Oriana S, Bohm S, Bresciani GL, Spatti G, Zunino F (1996) A comparative study of p53 gene mutations, protein accumulation, and response to cisplatin-based chemotherapy in advanced ovarian carcinoma. Cancer Res 56: 689-693

Russell P (1994) Surface epithelial-stromal tumours of the ovary. In Blaustein's Pathology of the Female Genital Tract, Kurman RJ. (ed) pp 705 - 782. Berlin Heidelberg, New York: Springer-Verlag

Ryan KM, Ernst MK, Rice NR, Vousden KH (2000) Role of NF-kappaB in p53 - mediated programmed cell death. Nature 404: 892 - 897 
Scheid MP, Duronio V (1998) Dissociation of cytokine-induced phosphorylation of Bad and activation of $\mathrm{PKB} / \mathrm{akt}$ : involvement of MEK upstream of Bad phosphorylation. Proc Natl Acad Sci USA 95: $7439-7444$

Schuyer M, van der Burg MEL, Henzen-Longmans SC, Fieret JH, Klijn JGM, Look MP, Foekens JA, Stoter G, Berns EMJJ (2001) Reduced expression of BAX is associated with poor prognosis in patients with epithelial ovarian cancer: a multifactorial analysis of TP53, p21, BAX and BCL-2. Br J Cancer 85: $1359-1367$

Sengupta PS, McGown AT, Bajaj V, Blackhall F, Swindell R, Bromley M, Shanks JH, Ward T, Buckley CH, Reynolds K, Slade RJ, Jayson GC (2000) p53 and related proteins in epithelial ovarian cancer. Eur J Cancer 36: $2317-2328$

Shahin MS, Hughes JH, Sood AK, Buller RE (2000) The prognostic significance of p53 tumor suppressor gene alterations in ovarian carcinoma. Cancer 89: 2006-2017

Shimada M, Kigawa J, Kanamori Y, Itamochi H, Takahashi M, Kamazawa S, Sato S, Terakawa N (2000) Mechanism of the combination effect of wildtype TP53 gene transfection and cisplatin treatment for ovarian cancer xenografts. Eur J Cancer 36: $1869-1875$

Wang X, Martindale JL, Holbrook NJ (2000) Requirement for ERK activation in cisplatin - induced apoptosis. J Biol Chem 275: 39435-39443

Wen WH, Reles A, Runnebaum IB, Sullivan-Halley J, Bernstein L, Jones LA, Felix JC, Kreienberg R, El-Naggar A, Press MF (1999) p53 Mutations and expression in ovarian cancer: correlation with overall survival. Int $J$ Gynecol Pathol 18: 29-41 